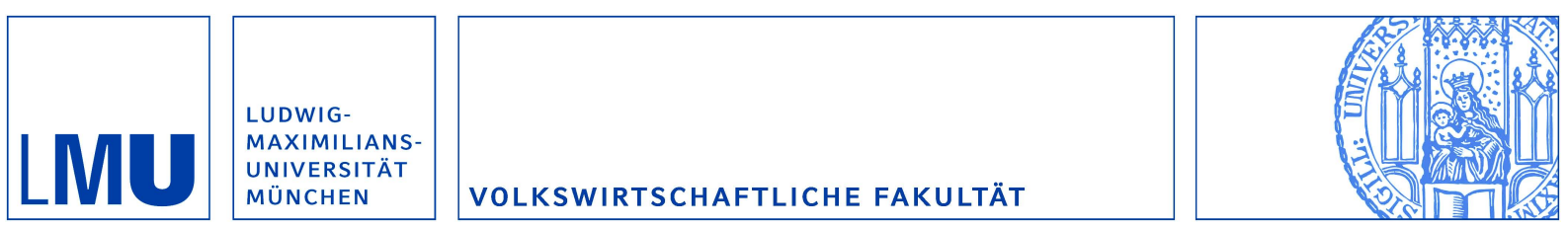

Boerner, Kira und Uebelmesser, Silke:

Migration and the Welfare State: The Economic Power of the Non-Voter?

Munich Discussion Paper No. 2005-24

Department of Economics

University of Munich

Volkswirtschaftliche Fakultät

Ludwig-Maximilians-Universitäł München

Online at https://doi.org/10.5282/ubm/epub.728 


\title{
Migration and the Welfare State: The Economic Power of the Non-Voter?
}

\author{
Kira Boerner \\ University of Munich* \\ Silke Uebelmesser \\ Center for Economic Studies, University of Munich, and CESifo ${ }^{\dagger}$
}

July 2005

\begin{abstract}
This paper investigates the impact of emigration on the political choice regarding the size of the welfare state. Mobility has two countervailing effects: the political participation effect and the tax base effect. With emigration, the composition of the constituency changes. This increases the political influence of the less mobile part of the population. The new political majority has to take into account that emigration reduces tax revenues and thereby affects the feasible set of redistribution policies. The interaction of the two effects has so far not been analyzed in isolation. We find that the direction of the total effect of migration depends on the initial income distribution in the economy. Our results also contribute to the empirical debate on the validity of the median-voter approach for explaining the relation between income inequality and redistribution levels.
\end{abstract}

JEL Classification: F22, H50, D31, D72

KEYWORDS: migration, redistribution, voting

${ }^{*}$ Department of Economics, University of Munich, Akademiestr. 1/III, 80799 Munich, Tel.: +49 892180 2766, Fax: +49 892180 2767, email: boerner@lmu.de

${ }^{\dagger}$ Center for Economic Studies, Schackstr.4, 80539 Munich, Tel.: +49 892180 5020, Fax: +49 89397303 , email: uebelmesser@lmu.de 


\section{Introduction}

One of the big puzzles concerning the political economy of the welfare state is why we only observe systems with limited redistribution. This is surprising because income distributions are usually skewed to the right. Thus, the net recipients of redistribution policies have more political decision-making power. The literature on endogenous limits to the size of the welfare state explains this observation by broadly following two lines: The first considers the self-interest of poorer citizens, i.e., their expectation of upwards mobility or their consideration of potential reactions of richer citizens. The second category looks at features of the political process such as the under-representation of the poor to explain the outcome of limited redistribution. ${ }^{1}$

In our paper, we focus on the first line of research. It has been strongly influenced by Meltzer and Richard (1981) who use the effects of taxation on the labor-leisure choice of citizens to derive a tax base effect that limits redistribution. The chosen setting is a closed economy. When voting, citizens rationally take into account that their fellow citizens might substitute labor with leisure as a reaction to higher taxes. A higher tax level can thus reduce the overall tax revenue. Together with the requirement of a balanced budget this creates an upper bound for redistribution policies and constrains the net recipients' demand for a large welfare state. The migration literature has contributed a similar argument within the context of an open economy: As tax increases may prompt net contributors to a redistributive system to leave the jurisdiction, migration leads to a tax base effect similar to the one found by Meltzer and Richard. The net recipients rationally take into account that the proportion of net contributors shrinks with higher tax rates. This limits their demand for more redistribution. Yet, when we consider the effects of migration, the tax base effect is not the only factor that influences the political decision.

The contribution of our paper is to identify two separate effects of mobility on the size of the welfare state and to analyze their interaction. These are related to the two different roles of citizens: one as taxpayers and the other as voters. First, if taxpayers leave a jurisdiction, migration lets the tax base shrink. Second, also the composition of the constituency that decides on redistributive policies changes with mobility. As some groups of voters emigrate, the political

\footnotetext{
${ }^{1}$ For a recent overview over these approaches, see Harms and Zink (2003).
} 
influence of the less mobile groups in the population increases. This shifts the political majority and therefore the preferred policy of the constituency. For example, if net contributors emigrate disproportionately more, ceteris paribus, the political majority's preference shifts towards a higher level of redistribution. The political participation effect thus works in the direction opposite to the tax base effect and increases the equilibrium size of the welfare state. The literature so far does not explicitly discuss the interaction of both effects. In our medianvoter model, we investigate how each of them shapes the redistribution outcome in political equilibrium. Thereby, we assess the overall impact of migration on the political choice of the size of the welfare state.

The purpose of this paper is to present a complete picture about the effects of migration on the welfare state within a political economy setup. In particular, we discuss the interaction of the tax base effect and the political participation effect and derive conditions under which the total effect is negative or positive.

We find that the direction of the total effect of migration depends on the initial income distribution in the economy. Moreover, our model naturally extends to a setting with mobile companies. With mobile companies, the tax base effect outweighs the political participation effect. Thus, increased mobility of companies might threaten existing welfare states.

Our results also contribute to the empirical debate on the validity of the median-voter approach for explaining the relation between income inequality and redistribution levels. This literature has not found convincing support for the hypothesis that a more skewed income distribution, with the median income below the average income, leads to more redistribution (Perotti, 1996, Lindert 1996, Milanovic, 2000). By taking into account both countervailing effects of mobility our model shows how the median voter approach may be reconciled with the data. In open economies, the tax base effect and the political participation effect counteract each other. It is therefore not surprising when the overall effect is smaller than expected or even insignificant.

The setup of the paper is as follows: In section 2, we discuss the related literature. We then set out the basic model in section 3. In section 4, we compare the impacts of the tax base effect and the political participation effect and discuss our results on the total effect of migration on the size of the welfare state. Section 5 concludes. 


\section{Related Literature}

Our paper links migration to the political economy of the welfare state. In a closed economy setting, redistribution is limited by potential tax-avoiding reactions of the net contributors. If voters take this into account, there is an endogenous upper bound on the size of welfare state (Meltzer and Richard, 1981). This holds even more in an open economy setting: Voters understand that high taxes lead to emigration of taxpayers and thereby reduce the tax revenue available for redistribution. Thus, they rationally refrain from demanding excessively high taxes. The total amount of redistribution is reduced by the possibility of migration (see, e.g., Wilson, 1982, Janeba and Raff, 1997, and the survey by Cremer et al., 1996). ${ }^{2}$

One strand of the migration literature uses a setup with competing jurisdictions or countries. In equilibrium, all citizens are distributed over the jurisdictions without further incentives to migrate. When mobility increases with income, in a setup with systems competition, several jurisdictions compete for the net contributors to the welfare state. Then, the tax base effect leads to a race to the bottom, resulting in the extreme in the abolition of the welfare state (Janeba and Raff, 1997).

This result can be avoided by enlarging the framework in several directions. With interregional transfers, the equilibrium outcome differs from the race to the bottom scenario. Kessler and Hansen (2004) show that when jurisdictions are linked by interregional transfers, redistributive policies can be asymmetric across regions. Interregional transfers act as a substitute for redistributive policies and can thereby restrain migration.

The result is also mitigated whenever mobility costs are considered, either as pecuniary costs or as a non-pecuniary attachment to home (e.g., Haupt and Peters, 2003, or Mansoorian and Myers, 1993). In multi-community models with migration costs, we get the well-known stratification result, going back to Tiebout (1956). Citizens with similar preferences for taxes and government spending or public good provision group together in one jurisdiction (see, e.g., Epple and Romer, 1991, Epple, Filimon, and Romer, 1984, Fernandez and Rogerson, 1996 and 1997, Glomm and Lagunoff, 1998, Hansen and Kessler 2001b, or Nechyba, 1997). Implicitly,

\footnotetext{
${ }^{2}$ An exception is Hindricks (2001) who analyzes the case where the poor are more mobile. He finds that the equilibrium amount of redistribution can increase in this setting. In particular, taxes can be inefficiently high as any improvement of the tax schedule, might attract voters with an interest in less redistribution. As lower taxes would shift the political equilibrium towards a smaller welfare state, the current majority tries to avoid this.
} 
there, citizens anticipate how the political equilibrium in their destination jurisdiction is affected by their migration decision and thus migrate strategically. Hansen and Kessler (2001a) include geographical size constraints into their model.

This literature, however, does not explicitly disentangle the tax base effect and the political participation effect. ${ }^{3}$ The reason is that most papers analyze the equilibrium after migration only. In equilibrium, by definition, no one migrates. This implies of course that the effects of migration on the tax base and on the constituency are already incorporated in the equilibrium outcome. Stratification then leads to the dominance of either the tax base or the political participation effect. For example, Epple and Romer (1991) find more redistribution, the poorer the jurisdiction. It is not entirely clear, however, how the final level of redistribution in a single jurisdiction is determined by outward mobility of tax payers and voters, compared to the situation before migration.

Our model has a different focus: We use a stylized setup where we focus on potential outmigration from a small (high-tax) country with a redistributive welfare state. The environment of that country, the destination of emigration, is assumed to be a large (low-tax) country with a small or no welfare state. From the perspective of the small country, the redistribution policy of the destination country is given. This implies that the potential migrants face a fixed outside option. Moreover, migration behavior in our model is such that we do not get stratification but have emigrants from all income groups in different proportions. This setup allows us to focus on the effects of outward migration on the tax base and on the composition of the constituency in the small country. In such a framework, also the political participation effect becomes visible.

Our political participation effect could also be implied by strategic considerations of politicians: Incumbents could deliberately use policies that induce emigration of a part of the citizens in order to shape their constituency and ensure reelection. Glaeser and Shleifer (2002) term this the "Curley Effect", after the Boston mayor James Curley who, in the first half of the

\footnotetext{
${ }^{3}$ To the best of our knowledge, the only contribution that explicitly considers the political participation effect is by Lorz and Nastassine (2004). In their citizen-candidate model, more mobile citizens prefer a smaller welfare state. As they are more prone to migrate, they have less incentives for political participation. Thus, the political influence is shifted towards the proponents of a larger welfare state. In another context, Bolton and Roland (1997) introduce an explicit discussion of effects similar to the tax base and the political participation effect. In their analysis of possible reasons for the breakup of a nation state the authors identify a political factor, arising due to different political preferences (which are, in turn, determined by the income composition) in the region, and a tax base factor, due to different income distributions across regions. Yet, except for the separation of a whole region, there is no migration.
} 
last century, ensured his political majority among the poor Irish inhabitants by implementing policies that induced richer citizens to emigrate into the suburbs. The authors show that such a behavior, while successful politically, can result in pareto inferior economic outcomes. ${ }^{4}$ In this model, we do not consider any strategic behavior of the political leaders. Instead, we use a pure median voter approach. As some citizens emigrate, the political participation effect shapes the constituency and thus determines the position of the median voter.

\section{The Model}

In our model, the citizens of our country can vote on the size of the welfare state, i.e., on the tax level and the associated redistributive transfers. In what follows, by size of the welfare state we understand the level of the income tax in the economy. Furthermore, citizens have the possibility to leave the country. We are interested in seeing how the case of a closed economy without migration where all citizens vote and pay taxes compares to the case of an open economy where migrants neither vote nor pay taxes in their country of origin. In this section, we first describe the basic features of our economy. Then, we discuss the voting game on the welfare state for the closed economy setting and the open economy setting with emigration. We derive the implications both for the composition of the constituency and the political decision on the size of the welfare state.

\subsection{Setup of the Model}

In our model, the redistributive welfare state is financed by a proportional income or wage tax $\tau$. It is determined in the political equilibrium. Redistribution is effectuated via lump-sum transfers $T$ benefiting all citizens. As we assume a balanced budget, the budget constraint is $T=\tau \bar{y}$ where $\bar{y}$ is the mean income of the population. Given this, the utility of a voter in income group $i$ is defined as

$$
u_{i}=(1-\tau) y_{i}+\tau \bar{y}-d \tau^{2}
$$

Each citizen in income group $i$ receives a gross wage income $y_{i}$ for supplying inelastically one unit of labor. The citizen pays taxes $\tau y_{i}$ and benefits from the lump-sum transfer $\tau \bar{y}$. With

\footnotetext{
${ }^{4}$ Other examples of such a strategic use of the political participation effect are Detroit's black mayor Coleman Young who discriminated against white inhabitants or the separatist Parti Quebecois, whose election in the 1970s induced out-migration of Non-Quebecians.
} 
$-d \tau^{2}$ we capture any distortions, other than migration, that arise due to the wage income tax, e.g., the distortions in the labor-leisure choices.

The income distribution in the population is given by the cumulative distribution function $F(y)$ with the continuous density function $f(y)$ for $y \in\left[0, y_{\max }\right] . f\left(y_{i}\right)$ thus gives us the mass of citizens with income $y_{i}$. The mean income $\bar{y}$ is given by

$$
\bar{y}=\int_{0}^{y_{\max }} y f(y) d y
$$

and the median income $y_{m}$ is implicitly defined by

$$
\int_{0}^{y_{m}} f(y) d y=\frac{1}{2}
$$

Assumption 1 The income distribution $f(y)$ is skewed to the right and unimodal. We thus have that $y_{m}<\bar{y}$.

With this assumption, we capture the empirically well-known shape of most real-world income distributions. ${ }^{5}$ It is standard in the migration literature (see, e.g., Hansen and Kessler, 2001a and 2004)

\subsection{Voting on the Welfare State: No Migration}

For the political decision on the size of the welfare state, i.e., the tax rate $\tau$, we use the median voter theorem. It is straightforward to see from the first-order condition of the citizen's utility maximization

$$
\frac{\partial u_{i}}{\partial \tau}=-y_{i}+\bar{y}-2 \tau d=0
$$

with $\frac{\partial^{2} u_{i}}{(\partial \tau)^{2}}=-2 d<0$ that each citizen of income group $i$ has a unique preferred tax rate $\tau_{i}^{*}$. As we rule out negative tax rates, we have

$$
\tau_{0, i}^{*}=\begin{array}{ll}
\frac{\bar{y}-y_{i}}{2 d} & \text { for } y_{i} \leq \bar{y} \\
0 & \text { for } y_{i}>\bar{y}
\end{array}
$$

where the subscript 0 denotes the case with no migration where neither the tax base effect nor the political participation effect are present. In order to be able to use the median-voter

\footnotetext{
${ }^{5}$ See, e.g. Burkhauser et al. (1996).
} 
theorem, we need that the preferences for $\tau$ are monotonic in the citizens' individual incomes $y_{i}$ such that we can order all citizens according to their incomes. This condition is fulfilled in our model: As we have that $y_{m}<\bar{y}$, the median must always lie in the part of the income distribution where citizens prefer a positive tax rate. In this part of the population, preferences for the tax rate are strictly monotonically decreasing with income (cf. (5)). Thus, the equilibrium tax rate in our economy is the tax rate preferred by the median voter. With conditions (3) and (2), we can state

Lemma 1 Without migration, the unique political equilibrium is

$$
\tau_{0}^{*}=\frac{\bar{y}-y_{m}}{2 d}>0
$$

Proof. We have that $\tau_{0}^{*}>0$ as with assumption 1 , the median income lies below the mean income.

We denote the equilibrium tax rate in the case with no migration with $\tau_{0}^{*}$. We assume that the distortion $d$ is high enough so that we get internal solutions for the tax rate, i.e. $\tau_{0}^{*} \leq 1$. For the case in lemma 1 , we would need at least that $d \geq \frac{\bar{y}-y_{m}}{2}$. In order to assure internal solutions for all cases, it is sufficient to assume:

\section{Assumption $2 d \geq \frac{y_{\max }}{2}$.}

We take $\tau_{0}^{*}$ as our benchmark for the analysis of the effects of migration on the size of the welfare state.

\subsection{Voting on the Welfare State: Migration}

We now introduce mobility in our setup. In this model, we focus on the effects of emigration on the political decision on the size of the welfare state to derive the implications when considering the two distinct effects - the tax base effect and the political participation effect: First, emigration affects the amount of tax revenues that are available for redistribution and may therefore restrict the set of feasible redistribution policies. Second, emigration changes the composition of the constituency and increases the political influence of the less mobile part of the population. ${ }^{6}$ With this model, we focus exclusively on the effects of emigration in one

\footnotetext{
${ }^{6}$ Generally, an open economy will experience both emigration and immigration. Yet, focussing on emigration only is not overly restrictive as explicitly taking immigration into account would reinforce the effects we identify
} 
country. Therefore, we model the recipient country of our emigrants as simply as possible. Let us assume that there is no welfare state in the destination country, i.e., the tax rate is zero. This assumption yields the most clear-cut results. However, any setup where the recipient country displays a smaller welfare state than the country of origin could easily be introduced and would preserve our results. Let us further assume that all individuals receive the same gross wages in both countries. In addition, each individual $j$ in group $i$ has an individual-specific component $\varepsilon_{i j}$ to her income in the destination country. It is related to the productivity abroad and known to the individual before the migration decision is taken. ${ }^{7}$ This component takes an additive form with respect to wage income such that income abroad for an individual $j$ of income group $i$ is then given by $y_{i}+\varepsilon_{i j}$. For each income group $y_{i}, \varepsilon_{i j}$ is distributed over $\mathbb{R}$ with density $g(\varepsilon)$ and the cumulative distribution function $G(\varepsilon) \cdot{ }^{8}$ Its mean is given by $\alpha=\int \varepsilon g(\varepsilon) d \varepsilon$. We do not have to specify variance and skewness of $g(\varepsilon)$, as we have the same distribution for each income group of citizens.

When citizens do not emigrate, they remain part of the redistributive system in their country of origin. They pay taxes proportional to their income, i.e., earn net income $y_{i}(1-\tau)$. In addition, they receive a lump-sum transfer of the size of the average per capita tax income. We denote the mean income after emigration with $\bar{y}_{\alpha}$. The citizens reach their individual emigration decision by considering the new redistributive system after emigration, taking the new mean income $\bar{y}_{\alpha}$ as given.

For a given tax rate, individuals then emigrate if and only if

$$
y_{i}+\varepsilon_{i j}>y_{i}(1-\tau)+\tau \bar{y}_{\alpha}-d \tau^{2} \Longleftrightarrow \varepsilon_{i j}>\tau\left(\bar{y}_{\alpha}-y_{i}\right)-d \tau^{2}
$$

For each income group $y_{i}$, there is thus an $\varepsilon_{i j}^{*}$ such that

$$
\varepsilon_{i j}^{*}=\tau\left(\bar{y}_{\alpha}-y_{i}\right)-d \tau^{2}
$$

in our model. For a model studying the political economy implications of immigration only, see Mazza and Van Winden (1996).

${ }^{7}$ For example, $\varepsilon_{i j}$ can be related to language skills in particular and communication skills in general with respect to different cultural environments.

${ }^{8}$ Equally, we could use distributions with a bounded support, i.e., $\underline{\varepsilon}$ and $\bar{\varepsilon}$, where $\left.\left.\underline{\varepsilon} \in\right]-\infty, 0\right]$ and $\bar{\varepsilon} \in[0,+\infty[$ and make additional assumptions to ensure some minimal and maximal emigration. It is crucial in our setup that for some individuals in each income group, the individual characteristic is negative. Otherwise, all net contributors would leave the redistributive system. 
Individuals with $\varepsilon_{i j}>\varepsilon_{i j}^{*}$ emigrate and those with $\varepsilon_{i j}<\varepsilon_{i j}^{*}$ stay in the home country. Of those $f\left(y_{i}\right)$ individuals with income $y_{i},\left(1-G\left(\varepsilon_{i j}^{*}\right)\right) \cdot f\left(y_{i}\right)$ leave the country and $G\left(\varepsilon_{i j}^{*}\right) \cdot f\left(y_{i}\right)$ decide not to migrate.

The higher the mean $\alpha$ of the distribution $G(\varepsilon)$, the more citizens will emigrate in each income group, given that the variance of the individual-specific components $\varepsilon_{i j}$ is kept constant. The reason is that the individual-specific components $\varepsilon_{i j}$ of the citizens are then on average higher, i.e., such that emigration leads to a higher income for more citizens. Note that we assume that the variance of the individual-specific components $\varepsilon_{i j}$ is kept constant, as otherwise we could construct constellations where the mean of the distribution increases while the mass of citizens has an $\varepsilon_{i j}$ below the emigration threshold. Yet, this assumption seems plausible as we think of the individual-specific components $\varepsilon_{i j}$ as language or communication skills. While the general opportunuties to acquire such skills can improve in an economy, the indivdual abilities to use such opportunities will generally not change.

We can thus use $\alpha$ to capture the general migration propensity in the population. ${ }^{9}$ Formally,

$$
\frac{\partial\left(1-G\left(\varepsilon_{i j}^{*}\right)\right)}{\partial \alpha}>0
$$

If we compare different income groups we unambiguously find that higher income groups are more prone to emigrate than lower income groups. The cutoff level $\varepsilon_{i j}^{*}$ is the smaller, the higher the income of citizens $y_{i}$

$$
\frac{\partial \varepsilon_{i j}^{*}}{\partial y_{i}}=-\tau<0
$$

This is very plausible, as richer citizens benefit less from the redistributive system or are even net contributors. Note that because some citizens will have very negative individualspecific characteristics $\varepsilon_{i j}$, some individuals from each income group of net contributors will always remain in the country.

It will turn out to be useful to see how the effect of the income changes with a change in the tax rate. For this, we look at

\footnotetext{
${ }^{9}$ The shape (variance and/or skewness) of the distribution of the individual-specific components $\varepsilon_{i j}$ would be another way to capture the migration propensity in the population. If, for each income group, the mass of citizens shifts in such a way that more citizens have individual-specific components $\varepsilon_{i j}$ above the emigration threshold, the overall propensity to emigrate is increased.
} 


$$
\frac{\partial^{2}\left(\varepsilon_{i j}^{*}\right)}{\partial y_{i} \partial \tau}=-1<0
$$

Thus, we have that an increase in the tax rate increases emigration more for higher income groups than for lower ones.

We can also look at the change in emigration behavior in response to a change in the tax distortion $d$. With a more distortive tax system, we get higher emigration. Formally,

$$
\frac{\partial \varepsilon_{i j}^{*}}{\partial d}=-\tau^{2}<0
$$

This is intuitive as citizens suffer from a distortive tax system when they stay in the country and can escape from it by emigrating.

For our analysis, it is convenient to summarize the emigration behavior in a general migration function. The share of citizens who leave the country as a function of their income $y$, the tax rate $\tau$, and the general propensity to emigrate in the population, $\alpha$, is given by $E=E(\alpha, \tau, y)$. We can summarize our findings on the emigration behavior by stating

Lemma 2 The share of citizens who emigrate is given by $E(\alpha, \tau, y)$. The proportion of emigrants increases with the overall propensity to migrate $\alpha$ and the income group $y_{i}, \frac{\partial E}{\partial \alpha}>0$, $\frac{\partial E}{\partial y}>0$. Furthermore, the proportion of citizens who emigrate in reaction to a tax increase is the higher, the higher the income group, i.e. $\frac{\partial^{2} E}{\partial y \partial \tau}>0$.

Proof. For the proof, see the discussion above. From our comparative statics result in (9) it immediately follows that $\frac{\partial E}{\partial \alpha}>0$. The mass of citizens in an income group with $\varepsilon_{i j}>$ $\varepsilon_{i j}^{*}$ increases with $\alpha$. From (10) is is clear that $\frac{\partial E}{\partial y}>0$. Finally, from (11), we get that the threshold level for emigration decreases - and therefore emigration increases - the more with the tax rate, the higher the income group, i.e., $\frac{\partial^{2} E}{\partial y \partial \tau}>0$.

Our emigration function $E(\alpha, \tau, y)$ is in line with two empirical observations. First, we have that $0<E(\alpha, \tau, 0)<E\left(\alpha, \tau, y_{\max }\right)<1$, i.e., the proportion of citizens who emigrate increases with the income of citizens and is bounded from below and above such that from each income group some individuals but never all emigrate. The rich are more prone to migrate than the poor as they are the net contributors to the redistributive system. This is true in particular if the destination country has a smaller, or, in the extreme, no welfare state. This view is 
supported by a number of empirical studies that document a positive correlation between the propensity to migrate and the education level of individuals where the education level can be taken as a proxy for lifetime income. ${ }^{10}$ Second, individuals are heterogeneous with respect to the impact of working abroad on their productivity, for example, due to different language skills. Thus, usually only some and not all individuals with a certain income leave the country.

The migration behavior as described by $E(\alpha, \tau, y)$ leads to a change in the income distribution in the population of the country. The ratio of poor to rich increases as disproportionately more rich than poor citizens emigrate. With migration, the income density changes to

$$
f_{\alpha}(y)=f(y)(1-E(\alpha, \tau, y))
$$

The after-emigration mass of the population is given by

$$
\begin{aligned}
F_{\alpha}\left(y_{\max }\right) & =\int_{0}^{y_{\max }} f_{\alpha}(y) d y=\int_{0}^{y_{\max }} f(y)(1-E(\alpha, \tau, y)) d y \\
& =\int_{0}^{y_{\max }} f(y) d y-\int_{0}^{y_{\max }} f(y) E(\alpha, \tau, y) d y<F\left(y_{\max }\right)=1 .
\end{aligned}
$$

In order to be able to get probability interpretations of the income distribution in the following, we use the normalization

$$
\frac{1}{n} \int_{0}^{y_{\max }} f_{\alpha}(y) d y=1 \Leftrightarrow n=\int_{0}^{y_{\max }} f_{\alpha}(y) d y=F_{\alpha}\left(y_{\max }\right)<1
$$

where $n$ denotes the number of the non-migrants.

\subsection{Voting on the Welfare State: Two Effects of Migration}

Migration has potentially two effects, the tax base effect and the political participation effect. Note that, with the emigration behavior captured by our emigration function $E(\alpha, \tau, y)$, the proportion of citizens who stay in the country depends on the tax rate $\tau$ that is chosen in the political equilibrium. Thus, there is an interaction between the migration decision and the voting decision. We assume a simultaneous time structure as it best captures the interdependencies that are present in a world with migration and voting.

With mobility, each citizen has to reach two decisions at the same time: the voting decision and the decision whether or not to emigrate. After the voting game and emigration, the new tax

\footnotetext{
${ }^{10}$ See, for example, for the issue of internal migration, Greenwood (1997) for the USA, Ledent (1990) for Canada, or Carillo and Marselli (2003) for the case of Italy.
} 
policy is implemented, the transfers are paid out and the individual utilities realize. Citizens decide whether or not to emigrate taking into account the new equilibrium tax rate. This tax rate is determined by the new majorities where those citizens who decide to leave the country do not participate in the voting game. Each citizen is able to derive which income group the new median voter will belong to and can thus calculate the equilibrium outcome for the welfare state. From the point of view of each individual citizen, the election outcome is thus given. As she is only one member of an income group, her individual emigration decision will leave the overall voting outcome unaffected. ${ }^{11}$ We can also think of our simultaneous time structure as the steady state of a dynamic process with alternating emigration and voting. Note further that it would be uncritical to assume migration before or after voting. In the first case, emigrants will not vote as they have already left the country. In the second case, those who anticipate that they will emigrate will not vote as they are not affected by the new tax rate.

For our main result, in order to capture the total effect of migration, we take into account that emigrants both refrain from voting and cease to pay taxes. We will discuss the result in the next section. In this section, we want to disentangle the two effects. For this purpose, we use a thought experiment and look at the two fictitious cases where, first, emigrants cease to vote and still pay taxes and second, emigrants still vote and cease to pay taxes. This means that we consider first the tax base effect and second the political participation effect in isolation.

\subsubsection{The Tax Base Effect}

When emigrants stop paying taxes, mobility reduces the total tax revenue in the home country. The amount of government revenue that is available for redistribution shrinks. This becomes clear when we look at the balanced budget constraint for our lump-sum transfers. With migration, the mean income $\bar{y}$ changes and is now given by $\bar{y}_{\alpha}=\frac{1}{n} \int_{0}^{y_{\max }} y f_{\alpha}(y) d y$. We call this effect the tax base effect.

Lemma 3 For the migration function $E(\alpha, \tau, y)$, the tax base effect of emigration always leads to a reduction of the mean income, i.e., $\bar{y}_{\alpha}<\bar{y}$, and thus for a given tax rate $\tau$ reduces the per capita lump-sum transfers in the economy, i.e., $T^{\alpha}<T$.

\footnotetext{
${ }^{11}$ This is true even for the median voter as we have many citizens of mass $f\left(y_{i}\right)$ of each income group $y_{i}$.
} 
Proof. The mean income of the after-emigration population is given by

$$
\begin{gathered}
\bar{y}_{\alpha}=\frac{1}{n} \int_{0}^{y_{\max }} y f(y)(1-E(\alpha, \tau, y)) d y=\frac{1}{n}\left[\int_{0}^{y_{\max }} y f(y) d y-\int_{0}^{y_{\max }} y f(y) E(\alpha, \tau, y) d y\right] \\
=\frac{\bar{y}-\int_{0}^{y_{\max }} y f(y) E(\alpha, \tau, y) d y}{\int_{0}^{y_{\max }} f(y)(1-E(\alpha, \tau, y)) d y} .
\end{gathered}
$$

For $\bar{y}_{\alpha}<\bar{y}$, this means that

$$
\frac{\bar{y}-\int_{0}^{y_{\max }} y f(y) E(\alpha, \tau, y) d y}{\int_{0}^{y_{\max }} f(y)(1-E(\alpha, \tau, y)) d y}<\bar{y}
$$

or

$$
\bar{y}-\int_{0}^{y_{\max }} y f(y) E(\alpha, \tau, y) d y<\bar{y} \int_{0}^{y_{\max }} f(y)(1-E(\alpha, \tau, y)) d y
$$

and

$$
\int_{0}^{y_{\max }} y f(y) E(\alpha, \tau, y) d y>\int_{0}^{y_{\max }} \bar{y} f(y) E(\alpha, \tau, y) d y
$$

For $\frac{\partial E}{\partial y}>0$, this must always be true. When disproportionately more rich citizens emigrate, the mean income of the emigrating population must be larger (left-hand side) than when all income groups emigrate proportionally to their initial weights in the population such that the average income of the migrants is equal to the no-emigration mean income $\bar{y}$ (right-hand side). We thus have $\bar{y}_{\alpha}<\bar{y}$. For a given tax rate $\tau$, this yields $T^{\alpha}=\tau \bar{y}_{\alpha}<T=\tau \bar{y}$.

To analyze in isolation how the tax base effect changes the equilibrium tax rate, we assume that citizens have the right to vote independently from their place of residence, i.e., there is no political participation effect. For this hypothetic case, we assume that their preferences are the same as in the absence of migration. Reasons for this could be that the emigrants still feel an attachment to home or plan to return to their country of origin in the future. Thus, the identity and the income $y_{m}$ of the median voter do not change with emigration.

As the benchmark, we look at the case where both non-migrants and migrants have to pay taxes. We know from our analysis (lemma 1) above, that then, the equilibrium tax rate is

$$
\tau_{0}^{*}=\frac{\bar{y}-y_{m}}{2 d} .
$$

We next consider the case where the tax base effect is present. That is, we assume that emigrants do not pay taxes once they have left the country. The mean income decreases to $\bar{y}_{\alpha}$ (cf. (15)). Citizen $i$ 's preferred tax rate is then given by

$$
\frac{\partial u_{i}}{\partial \tau}=-y_{i}+\bar{y}_{\alpha}-2 \tau d=0
$$


As we rule out negative tax rates, we have

$$
\tau_{t, i}=\begin{array}{ll}
\frac{\bar{y}_{\alpha}-y_{i}}{2 d} & \text { for } y_{i} \leq \bar{y}_{\alpha} \\
0 & \text { for } \quad y_{i}>\bar{y}_{\alpha}
\end{array}
$$

where the subscript $t$ indicates that only the tax base effect is present. We can again apply the median voter theorem as preferences decrease monotonically with income $y_{i}$. We thus get the equilibrium tax rate as the preferred policy of the median voter

$$
\tau_{t}^{*}=\begin{array}{ll}
\frac{\bar{y}_{\alpha}-y_{m}}{2 d} & \text { for } y_{m} \leq \bar{y}_{\alpha} \\
0 & \text { for } y_{m}>\bar{y}_{\alpha} .
\end{array}
$$

Note that we did not impose any restrictions on the migration function $E(\alpha, \tau, y)$ that would guarantee that the median voter $y_{m}$ always lies in the interval $\left[0, \bar{y}_{\alpha}\right]$. Thus, it is not excluded that the tax rate preferred by the median voter is zero.

We can now identify the tax base effect by comparing the equilibrium tax rates for the cases with and without migration $\tau_{t}^{*}$ and $\tau_{0}^{*}$.

Proposition 1 When all citizens vote, the tax base effect of migration strictly reduces the equilibrium tax rate, i.e., $\tau_{t}^{*}<\tau_{0}^{*}$.

Proof. The result follows directly from the comparison of conditions (6) and (19). We know from lemma 3 that the new mean income is lower than the one without migration, i.e., $\bar{y}_{\alpha}<\bar{y} \forall \alpha>0$. Thus, $\tau_{t}^{*}=\frac{\bar{y}_{\alpha}-y_{m}}{2 d}<\tau_{0}^{*}=\frac{\bar{y}-y_{m}}{2 d}$ for all possible realizations of $y_{m}$.

For the net contributors, emigration serves as a way to evade the tax. When staying, net contributors prefer a tax rate of zero. For the net recipients, it is optimal to restrain themselves and demand a lower tax rate than in the case without migration. Regardless of the position of the median voter to the left or the right of the new mean income, we thus always get a reduction of the tax rate. With this, we replicate the standard result in the literature, namely, that the tax base effect reduces the equilibrium tax rate and the size of the welfare state. However, emigration has a second effect, which is to shift the position of the median voter. We consider that in the following.

\subsubsection{The Political Participation Effect}

The second effect of migration concerns the political participation of emigrants. Once they leave the country, emigrants lose their right to vote. In reality, this is the case, for example, 
when citizens move from one jurisdiction to another inside a federal state. They then lose the right to vote in their jurisdiction of origin and automatically receive the franchise in their jurisdiction of destination. Also, emigrants might lose the incentives to vote as they have no stakes in the politics of their country of origin, although they would still retain voting rights as long as they did not change their nationality.

Whenever emigrants do not vote, we have the political participation effect. Emigration changes the composition of the constituency and thus the position of the median voter. The median income for the case with migration $y_{m, \alpha}$ is now implicitly given by

$$
\int_{0}^{y_{m, \alpha}} f_{\alpha}(y) d y=\int_{0}^{y_{m, \alpha}} f(y)(1-E(\alpha, \tau, y)) d y=\frac{1}{2} F_{\alpha}\left(y_{\max }\right) .
$$

Here, we do not need a normalization as the median is defined with respect to the afteremigration mass of citizens $F_{\alpha}\left(y_{\max }\right)$. Note that not only the mean but also the median income in the case with migration depends on the equilibrium tax rate, as $f_{\alpha}(y)$ depends on $\tau$.

We can state

Lemma 4 For the migration function $E(\alpha, \tau, y)$, the political participation effect of emigration always leads to a reduction of the median income, i.e., $y_{m, \alpha}<y_{m}$.

Proof. We have to show that with migration, the mass of the non-emigrating citizens to the left of the original median without migration, $y_{m}$, relatively increases, while the mass of citizens to the right of $y_{m}$ relatively decreases. This means we need

$$
\int_{0}^{y_{m}} f(y)(1-E(\alpha, \tau, y)) d y>\int_{y_{m}}^{y_{\max }} f(y)(1-E(\alpha, \tau, y)) d y
$$

or

$$
\int_{0}^{y_{m}} f(y) E(\alpha, \tau, y) d y<\int_{y_{m}}^{y_{\max }} f(y) E(\alpha, \tau, y) d y .
$$

The last inequality says that the mass of the emigrating citizens to the left of $y_{m}$ has to be smaller than the mass of the emigrating citizens to the right of $y_{m}$. This is trivially the case here as we have constructed the migration function such that the migration incidence increases with income, $\frac{\partial E}{\partial y}>0$. The loss of citizens due to migration to the right of the median is thus larger than to the left. It has thus to hold for the new median that $y_{m, \alpha}<y_{m}$ in order to achieve the balance. 
Richer citizens emigrate in relatively larger proportions. Therefore, the constituency, that is composed of all citizens who remain in the country, becomes poorer. The income distribution of the after-emigration mass of citizens shifts towards lower incomes and the median income after emigration is lower than without migration.

To analyze the outcome for the tax rate when only the political participation effect is present, we assume that all non-migrants and all emigrants pay taxes, i.e., there is no tax-base effect. Again, our benchmark is the case without migration, given by lemma 1,

$$
\tau_{0}^{*}=\frac{\bar{y}-y_{m}}{2 d}
$$

Next, we consider the scenario where emigrants do not vote. As emigrants still pay taxes, the mean income is the same as without migration, i.e., $\bar{y}$. The preferred tax rate of voter $i$ is

$$
\tau_{p, i}=\begin{array}{lll}
\frac{\bar{y}-y_{\alpha}^{i}}{2 d} & \text { for } y_{i} \leq \bar{y} \\
0 & \text { for } y_{i}>\bar{y}
\end{array}
$$

where the subscript $p$ denotes the presence of the political participation effect only. Now, with emigration, the median income changes to $y_{m, \alpha}$ as defined in condition (20). The equilibrium tax rate in this case is

$$
\tau_{p}^{*}=\frac{\bar{y}-y_{m, \alpha}}{2 d}>0 .
$$

In lemma 4, we have shown that migration always moves the median voter towards lower incomes. Thus, as in our benchmark case, the income of the median voter is always left of the mean income. Therefore, the median voter will always prefer a strictly positive tax rate.

We can now identify the political participation effect by comparing the equilibrium tax rates $\tau_{0}^{*}$ and $\tau_{p}^{*}$ :

Proposition 2 When all citizens pay taxes, the participation effect of migration strictly increases the equilibrium tax rate, i.e., $\tau_{p}^{*}>\tau_{0}^{*}$.

Proof. The result follows directly from a comparison of conditions (6) and (23). We have that $\tau_{p}^{*}=\frac{\bar{y}-y_{m, \alpha}}{2 d}>\tau_{0}^{*}=\frac{\bar{y}-y_{m}}{2 d}$ as we have shown in lemma 4 that $y_{m, \alpha}<y_{m}$.

Due to the political participation effect, the composition of the constituency is changed. The median income shifts to the left. Ceteris paribus, the new median voter thus prefers a larger size of the welfare state. 


\section{Results: Comparison of the Equilibrium Tax Rates}

\subsection{The Total Effect of Migration}

So far, we have seen that emigration leads to two opposite effects: First, due to the tax base effect, emigration reduces the size of the welfare state. When voting on the tax rate, citizens take into account that high tax rates trigger high emigration and thereby reduce the tax base. Therefore, the median voter ceteris paribus restrains her demand for a high tax rate. Second, we have the political participation effect that increases the size of the welfare state. As disproportionately more rich citizens emigrate, the median voter becomes poorer and ceteris paribus prefers a higher tax rate. Thus, both the mean income and the position of the median voter change as described in lemmas 3 and 4 . The total effect of emigration is ambiguous. It depends on which of the two opposite effects dominates. In order to asses the total effect of emigration on the size of the welfare state, a more structured analysis is needed.

The equilibrium in our model is defined as follows: It is a pair of a tax rate and a median voter where, first, the tax rate is the preferred tax rate of the median voter and second, the median voter is the median of the after-emigration population given the tax rate. Formally, we have $\tau_{t p}^{*}=\tau_{t p}^{*}\left(y_{m, \alpha}\left(\tau_{t p}^{*}\right)\right)$ where the tax rate chosen by the new median voter in equilibrium, $\tau_{t p}^{*}$, when both the tax base effect and the political participation effect are present, is given by

$$
\tau_{t p}^{*}=\frac{\bar{y}_{\alpha}-y_{m, \alpha}}{2 d}
$$

Due to simultaneous voting and emigration, we have $\bar{y}_{\alpha}=\bar{y}_{\alpha}\left(\tau_{t p}^{*}\right)$ and $y_{m, \alpha}=y_{m, \alpha}\left(\tau_{t p}^{*}\right)$.

Note that, as our emigration function is such that disproportionately more citizens with higher incomes emigrate, also the after-emigration median will always have a lower income than the after-emigration mean income, i.e., $y_{m, \alpha}<\bar{y}_{\alpha}$. The after-emigration income distribution $f_{\alpha}(y)$ can never become skewed to the left. Therefore, we know that the median income lies in the range of incomes where citizens prefer a positive tax rate and where the tax preferences strictly monotonically decrease with income.

Because of the two opposite effects of migration on the equilibrium tax rate, it is impossible to analytically pin down whether emigration reduces or increases the size of the welfare state. Both directions are in general possible. This has so far been overlooked in most analyses. In all cases, migration shifts the mean income as well as the income of the median voter downwards. 
We can state

Proposition 3 The change from a closed to an open economy with emigration leads to a larger welfare state, $\tau_{t p}^{*}>\tau_{0}^{*}$, if and only if the political participation effect dominates the tax base effect, i.e.,

$$
y_{m}-y_{m, \alpha}>\bar{y}-\bar{y}_{\alpha}
$$

Emigration reduces the size of the welfare state if and only if the reverse relation holds.

Proof. Whether the welfare state is increased or decreased depends on the relative sizes of the two shifts of the median and the mean income due to migration. For the equilibrium tax rate, we get $\tau_{t p}^{*} \gtrless \tau_{0}^{*} \Longleftrightarrow y_{m}-y_{m, \alpha} \gtrless \bar{y}-\bar{y}_{\alpha}$. When migration has a larger impact on the median than on the mean income, the size of the welfare state is increased. But when the mean income is shifted by more, migration reduces the size of the welfare state.

We have identified the characteristics of the migration function in lemma 2: The rich are more prone to emigrate than the poor. Whether median or mean are shifted by more, then depends on the original income distribution in the economy. Note that for our results, we did not require any restrictions for the income distribution, apart from unimodality and skewness to the right. It is possible to construct examples for both cases. In the following, we discuss two of these examples.

First, in order to see a case where the political participation effect dominates the tax base effect and migration increases the size of the welfare state, think of an income distribution where income is almost uniformly distributed over the income groups $y_{i} \in\left[0, y_{\max }\right]$. Then, without migration, we have that the median income is only slightly lower than the mean income - both being close to $\frac{y_{\max }}{2}$. Approximatively, we can think of a uniform distribution where the median voter earns the mean income. When we introduce emigration where proportionally more rich than poor emigrate, the income distribution of those who remain in the country becomes skewed to the right. Thus, the median income is reduced by more than the mean income. Compared to our starting point with mean and median income almost equal, this means that here, the median income is more strongly affected than the mean income. Our model predicts that in cases where the income distribution is more or less uniform - according to proposition 3 - the 
political participation effect dominates and migration increases the size of the welfare state. The poorer median voter demands a higher tax rate in equilibrium.

Second, an example for the case where the tax base effect dominates can be described with an even simpler income distribution: Let us assume that we have only two income groups, $y_{\text {low }}$ and $y_{\text {high }}$, where $y_{\text {low }}<y_{\text {high }}$ and due to our assumption of skewness $f\left(y_{\text {low }}\right)>f\left(y_{\text {high }}\right)$. Then, the median voter has income $y_{l o w}$. The mean income, on the other hand, lies between $y_{\text {low }}$ and $y_{\text {high }}$. When we now introduce emigration where disproportionately more rich than poor citizens emigrate, the median income remains at $y_{\text {low }}$. The mean income is, however, reduced. Thus, we have that migration shifts the mean income more than the median income. This means - according to proposition 3 - that the tax base effect dominates the political participation effect and that migration reduces the size of the welfare state.

Note that our model would yield identical results for the case of a disproportionate immigration of the poor. As soon as the immigrants become part of the redistributive system and members of the political constituency, such an immigration reduces the mean income and shifts the median income to the left. This corresponds to our result from proposition 3. Allowing both for emigration and immigration would amplify the tax base and the participation effect: Emigration of the rich and immigration of the poor, both triggered by a large welfare state, reduces the average tax revenues. Likewise, the median voter becomes poorer because both richer voters leave and poorer voters join the political constituency

\subsection{Comparative Statics}

In the last section, we have compared two cases: the closed and the open economy. For an already open economy, we are interested in finding how a change in the migration propensity of the population influences the results. To see how a marginal increase in openness affects the size of the welfare state, we look at a marginal change of $\alpha$ (the mean of the individual-specific components $\varepsilon_{i j}$ ), keeping the variance of the individual-specific components $\varepsilon_{i j}$ constant. A marginal increase of $\alpha$ means that the destination country becomes more attractive, for example, as citizens acquire more language skills or other internationally applicable qualifications.

In order to analyze the effect of an increased migration propensity, we totally differentiate

(24). $\frac{d \tau_{t p}^{*}}{d \alpha}$ captures the effect of emigration on the equilibrium tax rate where an increase in 
the propensity to emigrate, $\alpha$, leads to higher emigration for all income groups (see lemma 2). Whether the equilibrium tax rate is larger or smaller for higher $\alpha$, i.e., whether the political participation effect or the tax base effect dominates, depends on the relative changes of the mean and median income. We can state

Proposition 4 Emigration increases the size of the welfare state, i.e., $\frac{d \tau_{t p}^{*}}{d \alpha}>0$, if and only if the effects of emigration on the median income are absolutely larger than on the mean income as given by

$$
\underbrace{\left(\frac{\partial \bar{y}_{\alpha}}{\partial \alpha}+\frac{\partial \bar{y}_{\alpha}}{\partial \tau}\right)}_{<0}-\underbrace{\left(\frac{\partial y_{m, \alpha}}{\partial \alpha}+\frac{\partial y_{m, \alpha}}{\partial \tau}\right)}_{<0}>(2 d) .
$$

Emigration reduces the size of the welfare state, i.e., $\frac{d \tau_{t p}^{*}}{d \alpha}<0$, if and only if the reverse relation holds.

Proof. For the proof, take the total derivative $\frac{d \tau_{t p}^{*}}{d \alpha}$,

$$
\frac{d \tau_{t p}^{*}}{d \alpha}=\frac{\frac{\partial \bar{y}_{\alpha}}{\partial \alpha}-\frac{\partial y_{m, \alpha}}{\partial \alpha}}{(2 d)-\frac{\partial \bar{y}_{\alpha}}{\partial \tau}+\frac{\partial y_{m, \alpha}}{\partial \tau}}
$$

and set $\frac{d \tau_{t p}^{*}}{d \alpha}>0$. This yields condition (26).

In order to sign the partial derivatives, consider again lemma 2. From there, we know that the proportion of emigrating citizens in each income group increases with the propensity to migrate $\alpha, \frac{\partial E}{\partial \alpha}>0$. Moreover, we know that more citizens emigrate from an income group, the higher the income, $\frac{\partial E}{\partial y}>0$. If the overall migration propensity increases, this means that disproportionately more rich citizens emigrate. Therefore, as with the opening up of a closed economy (see lemmas 3 and 4), also with a marginal increase of the migration propensity $\alpha$, mean and median income must be reduced. We thus get that $\frac{\partial \bar{y}_{\alpha}}{\partial \alpha}<0$, and $\frac{\partial y_{m, \alpha}}{\partial \alpha}<0$.

Now, consider the derivatives $\frac{\partial \bar{y}_{\alpha}}{\partial \tau}$ and $\frac{\partial y_{m, \alpha}}{\partial \tau}$. They arise due to the simultaneous structure of our voting and emigration decisions. A marginal increase in the migration propensity $\alpha$ changes the equilibrium tax rate. $\frac{\partial \bar{y}_{\alpha}}{\partial \tau}$ and $\frac{\partial y_{m, \alpha}}{\partial \tau}$ show the effect of a change in the equilibrium tax rate on the after-emigration mean and median income. We know that higher income groups are more prone to emigrate. $\frac{\partial^{2} E}{\partial y \partial \tau}>0$ in lemma 2 tells us that this income effect is reinforced with an increase in the income tax level. Then, it also has to be the case that mean and median income are reduced by a tax increase, i.e., that $\frac{\partial \bar{y}_{\alpha}}{\partial \tau}<0$, and $\frac{\partial y_{m, \alpha}}{\partial \tau}<0$. 
Overall, we thus get

$$
\frac{d \tau_{t p}^{*}}{d \alpha}=\frac{\overbrace{\frac{\partial \bar{y}_{\alpha}}{\partial \alpha}}^{<0}-\frac{\overbrace{\partial y_{m, \alpha}}^{<0}}{\partial \alpha}}{(2 d)-\underbrace{\frac{\partial \bar{y}_{\alpha}}{\partial \tau}}_{<0}+\underbrace{\frac{\partial y_{m, \alpha}}{\partial \tau}}_{<0}}
$$

Condition (26) follows directly.

The first term on the left hand side of condition (26) shows the change in the mean income due to emigration. In total, the mean income is reduced by migration. The first part, $\frac{\partial \bar{y}_{\alpha}}{\partial \alpha}<0$, captures the fact that a larger propensity to emigrate in the population reduces the mean income. The second part, $\frac{\partial \bar{y}_{\alpha}}{\partial \tau}<0$, is due to the political choice of the tax rate. As the tax rate increases, more citizens from higher income groups emigrate. This reduces the mean income. The second term on the left hand side shows the shift of the position of the median voter due to emigration. Also the median income is always reduced by migration. Here, again, the first part, $\frac{\partial y_{m, \alpha}}{\partial \alpha}<0$, captures the fact that a higher propensity to emigrate in the population reduces the mass of rich citizens relative to poorer citizens. Thus, the median voter becomes poorer. The second part, $\frac{\partial y_{m, \alpha}}{\partial \tau}<0$, shows that an increase in the tax rate, which in turn triggers more emigration of the rich, leads to a further shift to the left of the median voter.

Intuitively, condition (26) says that the equilibrium tax rate increases with migration whenever the income of the median voter is shifted by at least $(2 d)$ more than the mean income. ${ }^{12}$ In this case, the political participation effect dominates the tax base effect. Even though the new median voter takes into account that emigration reduces the tax base with an increasing tax rate, she is sufficiently poor (or the change of the tax base is sufficiently small) to still demand a tax rate that is higher. The tax base effect, however, dominates for the opposite case, namely if the mean income is relatively more affected than the median income. The (slightly) poorer median voter is in favor of a smaller welfare state and thus a smaller tax rate to avoid a large reduction of the tax base.

\footnotetext{
${ }^{12}$ The total derivative (27) also shows that the equilibrium tax rate has to be lower, the larger the distortion. This is intuitive as emigration incentives depend on the tax rate. When the tax rate is low ex ante, the incentives to migrate are less pronounced. Then, also the effects of migration should be smaller.
} 


\section{Conclusions}

The effect of migration on the size of the welfare state is ambiguous. We have shown that it does not suffice to consider the tax base effect only, as the results can be overturned by the political participation effect. Which case is relevant for a particular economy is in the end an empirical question. The tax base effect ceteris paribus limits the demand for higher tax rates as citizens rationally anticipate that higher taxes induce migration and thereby reduce the amount that is available for redistribution. In contrast, the political participation effect increases the equilibrium tax rate as the identity of the median voter changes. The new median voter has a lower income and thus ceteris paribus prefers a larger welfare state.

With mobile companies, we intuitively get the unambiguous result where the tax base effect outweighs the political participation effect and the equilibrium size of the welfare state is reduced. In recent years, companies have quite often threatened to move abroad as a reaction to increased tax rates. They use this threat in order to exert pressure on politicians. Our model shows one reason why such a threat can be successful, even though it does not consider any lobbying activities: When companies move abroad, they will usually cease to pay taxes in their country of origin (unless they only set up foreign subsidiaries). Thus, with the "emigration" of companies, we have a - very often substantial - reduction of the tax base. On the other hand, as most employees usually do not follow, the political participation effect is rather weak. ${ }^{13}$ In this case, we therefore have a clear dominance of the tax base effect. Our model thus predicts that an increased mobility of companies leads to a reduction in the size of the welfare state. This is a development that we can observe in many industrialized countries today.

We can sum up our main results by relating them to the title of our paper. The economic power of the non-voters, i.e., the emigrants, drives the tax rate down because of the tax base effect. This is, however, partially or totally counteracted by the political power of those who stay in the country. When the effect of the shift of political power towards lower income groups is stronger than the reduction of the tax revenue due to emigration, the equilibrium tax rate might even increase. For this case, we miss an important part of the picture if we neglect the political participation effect and focus on the tax base effect only.

\footnotetext{
${ }^{13}$ If some of the employees become unemployed, the median income might be reduced by a small extent, but much less than in the case of emigration by citizens.
} 
Recognizing both effects could also contribute a new aspect to the empirical debate. Many cross-country studies that ask whether income inequality affects the size of the welfare state do not find a significant relationship (see, e.g., Perotti, 1996, Lindert 1996, Milanovic, 2000). From this, the authors conclude that the median voter approach is not appropriate to explain redistribution outcomes and other features of the political process have to be added. In the framework of our model, the median voter approach could be saved: We show that as tax base effect and political participation effect work in opposite directions, it is the relative strength of the two effects that matters. This is determined by the relative responses of mean and median income to migration pressure and not by their absolute distance. As in particular the political participation effect only occurs in open economies, the inclusion of a country's openness in empirical studies might provide additional insights. 


\section{References}

[1] Bolton, Patrick, and Gérard Roland (1997): The Breakup of Nations: A Political Economy Analysis, Quarterly Journal of Economics 112(4), 1057-1090

[2] Burkhauser, Richard V., Amy D. Crews, Mary C. Daly, and Stephen P. Jenkins (1996): Income Mobility and the Middle Class - AEI Studies on Understanding Inequality, Washington, DC: American enterprise Institute Press

[3] Carillo, Maria Rosaria, and Ricardo Marselli (2003): Internal Migration and Search Costs in Italy: The Role of the Regional Production System, mimeo

[4] Cremer, Helmuth, et. al. (1996): Mobility and Redistribution: A Survey, Public Finane 51(3), 325-352

[5] Fernandez, Raquel, and Richard Rogerson (1996): Income Distribution, Communities, and the Quality of Public Education, Quarterly Journal of Economics 111(1), 135-164

[6] Fernandez, Raquel, and Richard Rogerson (1997): Keeping People Out: Income Distribution, Zoning, and the Quality of Public Education, International Economic Review 38(1), $23-42$

[7] Epple, Dennis, and Thomas Romer (1991): Mobility and Redistribution, Journal of Political Economy 99(4), 828-858

[8] Epple, Dennis, Radu Filimon, and Thomas Romer (1984): Equilibrium among Local Jurisdictions: Toward an Integrated Treatment of Voting and Residential Choice, Journal of Public Economics 24, 281-308

[9] Glaeser, Edward L., and Andrei Shleifer (2002): The Curley Effect, NBER working paper No. 8942

[10] Glomm, Gerhard, and Roger Lagunoff (1998): A Tiebout Theory of Public vs Private Provision of Collective Goods, Journal of Public Economics 68, 91-112

[11] Greenwood, Michael J. (1997): Internal Migration in Developed Countries, in: Rosenzweig, Mark R., and Oded Stark (eds): Handbook of Population and Family Economics, Volume 1B, Amsterdam: Elsevier

[12] Hansen, Nico A., and Anke S. Kessler (2004): Interregional Redistribution and Mobility in Federations: A Positive Approach, CEPR Discussion Paper NO. 4576

[13] Hansen, Nico A., and Anke S. Kessler (2001a): The Political Geography of Tax H(e)avens and Tax Hells, American Economic Review 91(4), 1103-1115

[14] Hansen, Nico A., and Anke S. Kessler (2001b): (Non-)Existence of Equilibria in Mulitcommunity Models, Journal of Urban Economics 50, 418-435 
[15] Harms, Philipp, and Stefan Zink (2003): Limits to Redistribution in a Democracy: A Survey, European Journal of Political Economy 19, 651-668

[16] Haupt, Alexander, and Wolfgang Peters (2003): Voting on Public Pensions with Hands and Feet, Economics of Governance 4, 57-80

[17] Hindricks, Jean (2001): Mobility and Redistributive Politics, Journal of Public Economic Theory 3(1), 95-120

[18] Janeba, Eckhard, and Horst Raff (1997): Should the Power to Redistribute Income be (De-)Centralized? An Example, International Tax and Public Finance 4, 453-461

[19] Ledent, Jacques (1990): Canada, in: Nam, C.B., W.J. Serow, and D. F. Sly (eds.): International Handbook on Internal Migration, New York: Greenwood Press, 47-61

[20] Lindert, Peter H. (1996): What Limits Social Spending?, Explorations in Economic History $33,1-34$

[21] Lorz, Oliver, and Stanislav Nastassine (2004): Political Participation of Mobile Citizens and the Welfare State, CESifo Economic Studies 50, 647-662

[22] Mansoorian, A., Myers, G.M. (1993): Attachment to Home and Efficient Purchases of Population in a Fiscal Externality Economy, Journal of Public Economics 52, 117-132

[23] Mazza, Isidoro, and Frans van Winden (1996): A Political Economic Analysis of Labor Migration and Income Redistribution, Public Choice 88, 333-363

[24] Meltzer, Allan H., and Scott F. Richard (1981): A Rational Theory of the Size of Government, Journal of Political Economy 89(5), 914-927

[25] Milanovic, Branko (2000): The Median-Voter Hypothese, Income Inequality, and Income Redistribution: an Empirical Test with the Required Data, European Journal of Political Economy 16, 367-410

[26] Nechyba, Thomas J. (1997): Existence of Equilibrium and Stratification in Local and Hierarchical Tiebout Economies with Property Taxes and Voting, Economic Theory 10, $277-304$

[27] Perotti, Roberto (1996): Growth, Income Distribution, and Democracy: What the Data Say, Journal of Economic Growth 1, 149-187

[28] Tiebout, Charles (1956): A Pure Theory of Local Expenditures, Journal of Political Economy $64,416-424$.

[29] Wilson, John D. (1982): Optimal Linear Income Taxation in the Presence of Emigration, Journal of Public Economics 18, 363-379 